\title{
Prevalence of Depression in Port Harcourt Prison
}

\section{Uche Nwaopara ${ }^{1 *}$ and Princewill Stanley ${ }^{2}$}

${ }^{1}$ Akwa Ibom State Civil Service, Psychiatry Hospital, Eket, Akwa Ibom State, Nigeria

${ }^{2}$ Department of Neuropsychiatry, University of Port Harcourt, Teaching Hospital, Nigeria

\begin{abstract}
Background/Objectives: Imprisonment has been associated with mental illness, especially depression.

Aims/objectives: To investigate the prevalence of depressive disorders among inmates of Port Harcourt Prisons, South, Nigeria.

Methods: Through stratified random sampling, 400 prisoners were interviewed using the Depression component of WHO SCAN in a 2-stage design after having been screened with the Beck Depression Inventory (BDI). The study was descriptive in nature and used psychometric evaluation. A questionnaire with socio- demographic was administered along with the Beck Depression Inventory. The author performed bivariate and multivariate analysis regarding depression. SPSS Version 17, was used for analysis and test of significance was set at $p<0.05$.

Findings: 169 subjects presented with depression according to the BDI. However SCAN revealed a prevalence of $59(14.8 \%)$ for mild depression with somatic features, $57(14.2 \%)$ for moderate depression with somatic features, $25(6.2 \%)$ severe depression without psychotic features, while $18(4.5 \%)$ had severe depression with psychotic features. The overall true prevalence of depression was $37 \%$. Socio-demographic factors were found to be statistically significant included age (with being older acting as a protective factor), marital status, and place of living. Multiple Logistic regression analysis, however, revealed that the strongest predictors of depression among the subjects, were living in the urban area (OR: $0.31, \mathrm{Cl}=0.14-0.68, \mathrm{p}<0.01$ ), when correcting for confounders.
\end{abstract}

Discussion/Conclusions: The prevalence of depression was found to be high. Most of those identified were neither diagnosed nor received treatment. Undetected, under-detected and under-treated depression in the prisoners is an increasing public health problem.

Keywords: Prevalence; Prison; Penal; Depression

\section{Introduction}

Prison is an ancient institution, where diverse types of people, who had run afoul of the law, some of them possibly innocent, live [1,2]. Mental disorders occur frequently in the context of incarceration [2]. Related to this, is the fact that imprisonment may lead to the development of mental illness, especially depression [2].

The prison environment neutralizes the formation and development of basic human values, contributes to stigmatization, alters the convict's conduct and leads to temporary or even irreversible psychic sequelae $[1,2]$. Evidence suggests that imprisonment conditions can lead to anxiety, depression, self-harming or heteroaggressive behavior, obsessions, psychoactive substance abuse and suicide. There is no agreement in the literature on the causal relationship between confinement and mental disorders [2-4]. In addition to feelings of inadequacy, important feelings in imprisoned people are anticipated suffering in life outside of incarceration, fear of family abandonment, guilt for being absent from raising and educating their children, losing their right to the social importance of work, identity loss, social discrimination that impairs prospects for working outside of the criminal context and social recognition [5]. All these contribute to the development of depression among incarcerated people.

In developing countries, the prevalence rates of depression are higher [6]. This is so because environmental factors that contribute to the genesis of depressive disorders are more preponderant [6]. These include high rates of poverty, a lack of social welfare and high rates of endemic infectious diseases, to mention just a few [7]. Gender differences exist with respect to effects of incarceration on both male and female inmates [8]. Mental health problems have been observed to be higher among incarcerated inmates compared to the general population and are a significant source of morbidity among prisoners [9].

DSM-1V and the new DSM-5, are in agreement that Major depression include diagnoses of unipolar affective disorder with at least 5 of 9 of the symptoms of low mood, loss of interest, changes in sleep and activity, loss of energy, guilt feelings, suicidality, and loss of concentration for nearly every day for a duration of at least 2 weeks [9]. In Nigeria, prevalence rates vary between $11-60 \%$ depending on the study setting [10]. The World Health Organization (WHO) buttressed this fact when it stated that Depression, which currently affects 5-10\% of the population, is set to become the second largest cause of disease burden by 2020 and is the third most common reason for primary care consultation [11].

Recognition and treatment of depression often takes place in primary healthcare, secondary, and tertiary institutions with trained and qualified personnel [11]. However, this level of personnel are lacking among prison staff, hence, the obvious difficulty in the assessment and treatment of this category of people, requiring special care [12]. This is made worse by the fact that the proportions of the prisoners with

*Corresponding author: Uche Adolphus Nwaopara, Consultant, Psychiatric hospital Eket, No 19, Egbelu Street Rumuodara Port Harcourt, Nigeria, Tel: +2348069008876; E-mail: mceeuche@yahoo.com

Received December 26, 2014; Accepted October 31, 2015; Published November 07, 2015

Citation: Nwaopara U, Stanley P (2015) Prevalence of Depression in Port Harcourt Prison. J Psychiatry 18: 340 doi:10.4172/2378-5756.1000340

Copyright: (c) 2015 Nwaopara U, et al. This is an open-access article distributed under the terms of the Creative Commons Attribution License, which permits unrestricted use, distribution, and reproduction in any medium, provided the original author and source are credited 
possible clinically diagnosable psychiatric morbidity and significant depressive symptoms are quite high [13].

This may be so because the health systems in developing countries is poorly organized and poorly funded, as compared with the health care system in industrialized countries [14]. Two major problems face correction/prisons administration today in the greater part of the globe - inadequate funding, and over-crowding. Nigeria is no exception. Nigeria is neither lacking in resources nor funds, but lacks appropriate funding and allocation policies, which leads to gross under funding of public institutions such as the prisons. Hence, the prisons staff, and inmates may suffer deprivation. In Nigeria, as in most countries, prison systems shoulder the burden of providing healthcare services. They are, however, ill-equipped to perform this responsibility, due to limited resources (human and capital), corruption and the ever-increasing number of inmates [14]. In many countries (including Nigeria), prison establishments are struggling to provide minimal mental health services to prisoners, and only a few have exposure to psychiatrists [15]. The provisions for the mentally disordered prisoners have also been observed to be inadequate [15]. Given the limited resources of most prisons, however, it seems doubtful whether most prisoners with these illnesses receive appropriate care [16]. Appropriate mental health interventions and care should be a priority for this population [17]. This care is expected to be in line with that mandated by the European Convention on Human Rights and other international charters [18] and according to the requirements of the Nigerian Health and Mental Health Policy.

Results from other studies, indicate that gender and age are the most consistent demographic predictors of health status and medical care utilization. Females are reported to have higher morbidity and higher numbers of medical encounters [19]. The experience of incarceration also appears to influence the physical and mental health of inmates, as self-reported health problems increase with in-mates duration of incarceration [19]. The impact of marital status, parental status, and social support (both inside and outside of the jail) on various dimensions of mental health has also been examined in other studies [20].

Available data indicate that imprisonment is severely stressful for many inmates [21]. This may be because prisons were not set up to be corrective; rather they were punitive, in the criminal justice system [21]. Prison environments, which are often characterized by gross infrastructural decay and poor amenities, are potentially damaging situations, and its negative psychological effects must be taken seriously, carefully evaluated, purposefully regulated and controlled [21]. To this end, incarceration should be viewed not only as a correctional opportunity but as an opportunity to engage clinical and social resources for the full benefit of these inmates [22]. Education and the implementation of specific stress-management programs to the inmates and officials may be beneficial to ensure that stress within prisons is confined to tolerable limits [22].

This study was undertaken because despite the high prevalence of depression among incarcerated people, there is a paucity of local data among inmates of prisons in Nigeria. Therefore, this study in the southsouth region of Nigeria was carefully undertaken, to provide data on the burden of depression, in the population of the prisoners particularly among the inmates of the Maximum Security Prisons in Port Harcourt, Nigeria. The study also provided data that may assist in the formulation of the necessary preventive and treatment strategies in the target population. To the best knowledge of the researcher and to the best of available literature, this is the first time a study on the prevalence of depression and correlates will be conducted at the Maximum security prison, in Port Harcourt or any of the prison facilities in Degema, Ahoada, and Elele, all in Rivers State, Nigeria in its 128 years of existence as a prison facility having been established in 1928 .

With this justification of the rationale for the study, it initially set out to test 3 hypotheses:

Risks for psychological problems and prevalence of mental illnesses like depression are high among the incarcerated.

Socio-demographic characteristics are predictors of depression among prison inmates.

Depression is a significant source of morbidity among prison inmates, which is a public health issue.

\section{Materials and Method}

\section{Location of the study}

The study was carried out at the Maximum Security Prison, located in Port Harcourt, Rivers State, Nigeria. The Port Harcourt Prisons was selected because it is a Maximum Security Prisons because offenders of all categories of crime, including awaiting trial, convicts, and condemned criminals of both sexes are kept here. It is one of the earliest remand institutions in Nigeria. It was established by the British Colonialists in 1928. The institution has a holding capacity of 804 inmates. However according to the daily prison posts, at the time of this research, the number of inmates fluctuates between 2,900 and 3,000, with variation in the number, as more inmates were either brought in or released. Out of a total prison population of 3,000 inmates, 2940 (98\%) were males, while $60(2 \%)$ were females. Out of these, 144 were convicts (140 males, 4 females), while 2600 were awaiting trial inmates, 2542 of whom were males, while 45 were females. 3 were considered lunatics ( 2 males and 1 female). 14 male inmates were serving life imprisonment jail terms while no female was serving a life sentence. There were 155 inmates on death row, having being condemned to death (145 males and 10 females).

\section{Design of the study}

This work is a cross-sectional descriptive study.

\section{Ethical considerations}

The permission for this study was obtained from the ethics committee of the University of Port Harcourt Teaching Hospital (UPTH), and approval received from the State Controller of Prisons, under whom the Maximum Security Prisons Port Harcourt is. All information obtained, were handled confidentially and this was maintained at all times. Data from participants were also given under anonymity. Research findings were made available to the Nigerian Prison Service, with the hope of ensuring a better medical care for the inmates.

\section{Sampling}

The official website of the Nigerian Prisons showed that there are 2,900 inmates at Port Harcourt prisons at the time of conducting this research. The study sample was determined according to the fine population correction (fpc) principle, postulated by Araoye [18], if there is no reasonable estimate, a projected population of 0.5 is recommended for calculating the required sample size. However, sample size when studying population more than 10,000 is calculated with the formula:

$$
\mathrm{n}=\frac{\mathrm{Z}^{2} \mathrm{pq}}{\mathrm{d}^{2}}
$$


Where,

$\mathrm{n}=$ is the sample size,

$\mathrm{Z}^{2}=$ is the abscissa of the normal curve that cuts off an area at the tails (1 - equals the desired confidence level, e.g., 95\%), usually set at 1.96 .

$\mathrm{d}=$ is the desired level of precision,

$\mathrm{p}=$ is the estimated proportion of an attribute that is present in the population $(0.5)$, and

$q=1-p(0.05)$ which corresponds to the degree of accuracy desired.

$$
\mathbf{n}=\frac{\mathrm{z}^{2} \mathrm{pq}}{\mathrm{d}^{2}} \quad \frac{(1.96)^{2}(0.50)(0.050)}{(0.05)^{2}}=384 .
$$

If the study population is above 10,000 , the required sample size would have been 384 . However, in this study, the population was 2,900 (less than 10,000), the required sample size was therefore calculated using the Finite Population Correction for Proportions formula:

$$
\mathrm{n}=\frac{\mathrm{n}_{0}}{1+\frac{\left(\mathrm{n}_{0}-1\right)}{\mathrm{N}}}
$$

Where, ${ }^{\mathrm{n}}=$ the desired sample size when population $<10,000$.

$\mathrm{n}_{\mathrm{o}}=$ the desired sample size when population is $>10,000$.

$\mathrm{N}=$ the estimated study population 2,900 in this study.

$$
\mathrm{n}=\frac{384}{1+\frac{(384-1)}{2900}}
$$

This gave a sample size of 339 .

Using an assumed non-response rate of $15 \%$, a corrected sample size using the formula:

$$
\frac{\text { Sample Size }}{100-15} \times 100=\frac{339}{0.85}=398.8
$$

Approximately, 400 were obtained to make room for nonresponders.

Stratified random sampling was used. The population was divided into two (2) homogenous groups based on gender, to ensure that, not only the overall population is represented, but also subgroups of the population. A systematic random sampling was done using the prisons register (sampling frame), and using the sampling interval size calculated using the formula:

$$
\mathbf{N} / \mathbf{n}=\mathbf{k}
$$

Where $\mathrm{N}$ is the Total Population (3000), $\mathrm{n}$ is sample size (400), while $\mathrm{k}$ is sampling interval size.

$$
\frac{3000}{400}=7.46 \text { (approximately 7) }
$$

Therefore every seventh $\left(7^{\text {th }}\right)$ inmate on the register in both the male and female sections of the prisons was selected. The study was carried out within 3 months when the required sample size was expectedly obtained because of the protocol of the Nigerian Prisons Service and the time of administration of the research instruments to the participants as well as, the need to reduce long waiting hours for the respondents.

The principle of proportional allocation was also used to determine the population from each of the 2 subgroups (nf) based on gender, to make up the sample size using the formula:

$$
\mathrm{nf}=\frac{\mathrm{n}}{\mathrm{N}} \mathrm{xS} \text {. }
$$

Where, $\mathrm{n}=$ (no of items in each stratum or subgroup),

$\mathrm{N}=$ Total number (Population) of persons in all strata.

$\mathrm{S}=$ Total number of samples to be selected.

The current sample frame at the time of data collection was used.

1. Males: $\mathrm{nf}=2940 / 3000 \times 400=392$ inmates.

2. Females: $\mathrm{nf}=60 / 3000 \times 400=8$ inmates.

\section{Inclusion criteria}

Those who gave their consent to participate in the study were serving different terms of prison sentence, those on awaiting trial list.

\section{Exclusion criteria}

Inmates who declined to give consent to participate in the study, inmates who were too ill to participate in the study and those who were floridly psychotic and so were difficult to be meaningfully engaged.

\section{Instruments}

\section{Socio-demographic questionnaire}

A questionnaire was designed for data collection and consisted of 3 sections (A-D): The proforma comprised questions pertaining to identification and socio-demographic data, including clinical information and penal characteristics. The subject's identification starts with a code (no names were used). Participants name and addresses were not included to ensure confidentiality and participants reassured of the confidentiality of the information obtained, age, ethnicity, marital status (married, non-married), educational level attained, profession, work, origin, place of living, family class, religion, and ethnic group. The instrument was self-administered and assistance given to those who were not adequately literate.

\section{Becks depression inventory}

The severity of depression was assessed using the Beck Depression Inventory [11]. This is a 21-item self- rated instrument which measures the presence and degree of depression in adolescents and adults. Each 21-item attempts to assess a specific symptom or attitude which appears to be specific to depressed patients and are consistent with descriptions of depression contained in the psychiatric literature. The instrument is independent of any particular theoretical bias. Each item consists of four (4) graded statements which are ranked and weighted to reflect severity. Values from $0-3$ are used in scoring each item and the total score ranges between $0-63$. A breakdown of the scoring system is: 1 10 (Normal), 11 - 20 (Mild), 21 - 30(Moderate)

\section{1 - 40 (Severe), $41+$ (Extreme).}

The limitation in the use of Becks Depression Inventory which is self-reported is that it may be prone to bias. It is also not a diagnostic tool and has to be used in conjunction with other tests in order to provide proper analysis of the subject's mental state. The strength however is that it has been used for over 25 years and widely validated globally $[11,12]$. Also the BDI is easy to complete and takes less than 5 minutes. It is very suitable as a screening instrument for depression. The internal consistency estimate of reliability Cronbach's alpha based on the present study was $\mathrm{a}=0.74$ and had a mean score of 15.7 . 


\section{Schedule for clinical assessment in neuropsychiatry (SCAN} 2.1)

Depression was diagnosed using the pen and paper version of the Depression Module of the Schedule for Clinical Assessment in Neuropsychiatry (SCAN 2.1) which is a semi-structured instrument to derive ICD-10 diagnosis. SCAN has been validated in a number of studies on depression [7]. Depression was diagnosed using the pen and paper version of the Depression Module of the Schedule for Clinical Assessment in Neuropsychiatry (SCAN 2.1) which is a semi-structured instrument. This instrument represents the latest stage in a 30-year line of development that began in the late 1950's, and an improvement on the Presence State Examination-9. It has 4 components: the PSE10, the Glossary of Differential Definitions, the Item Group Chechlist (IGC) and the Clinical History Schedule (CHS). The SCAN was developed by the World Health Organization (WHO) and National Institute of Health (NIH) Joint Project on Diagnosis in 1992, with J. K. Wing as the Chief Editor. It is used to diagnose a broader range of disorders than PSE 9 including eating, somatoform, substance abuse, and cognitive disorders. Data from the schedule can be recorded in a variety of ways: in the SCAN schedules themselves, in Coding Booklets, or by the computer program. The coding booklet will be used to record data in this study and the computer program with be used to process data entered from the SCAN schedule. Output can be presented as a series of options, including a range of profiles of symptoms and IGC scores, an index of definition, ICD - 10, DSM - IIIR, DSM-IV categories, and a pre-diagnostic profile of categories. In this study the ICD - 10 diagnoses will be derived. The use of this instrument requires training which this author obtained. The SCAN was chosen because it is an improvement on the PSE - 9 which has been extensively used and translated to more than 35 languages. The use of this instrument requires training which this author obtained. The investigator had received training in the use of SCAN in a training programme organized by the World Health Organization, in conjunction with the Faculty of Psychiatry, National Post Graduate Medical College of Nigeria. This instrument was researcher administered.

\section{Pilot Study}

This was carried out on 40 consenting inmates, who met the inclusion criteria but were not included in the final study. The rationale for the pilot study was grouped under several broad classifications process, resources, management and scientific. The process assessed the feasibility of the steps needed, as part of the main study. Examples included helping to determine recruitment rates, retention rates, eligibility criteria, clarity in determining who meets and who does not meet the eligibility requirements, and the understanding of items on the instruments used and the need for possible translation, which was discarded on the grounds of multi-ethnicity of the inmates. The aspect of resources, dealt with assessing time and budget problems. The management issues, covered potential human and data optimization problems such as personnel and data management issues among the prison inmates.

\section{Procedure}

It was a two stage design. The Socio-demographic questionnaire and the Becks Depression Inventory were administered to all. Only respondents with Becks Depression Inventory (BDI) score of 11 and above were administered the SCAN 2.1. There was also random selection and analysis of the negatives with the SCAN 2.1 instrument which was done in 1 in 10 of them.
Respondents were encouraged to provide their answers voluntarily after signing the informed consent form. Allowance was made for variation in time taken for this aspect of the interview. This was dependent on the symptoms and psychopathology and the ability of patient to understand and properly respond to questions asked, promptly. Many of such interviews would last 1 hour or longer because of the reasons adduced above.

The independent variable was Depression while the independent variable was the socio-demographic characteristics

\section{Data analysis and management}

Data was entered into a micro-computer and analyzed using the Statistical Package for Social Sciences (SPSS) software for windows version 17. Multiple logistic regressions helped to adjust for confounders and helped to determine the dependent predictors of depression among the target population of prison inmates. Statistical significance was set at $\mathrm{p}<0.05$. Data handling was confidential.

\section{Results and Analysis}

At the time of data collection, the prisoners were not taking any medication and were not being evaluated by a mental health specialist.

\section{Socio-demographic characteristics of prison inmates}

The 400 subjects involved in the study and interviewed, ranged in age from 14 to 90 years, with a mean age of 33.8 ( $S D \pm 14.42$ ), most of whom were between the ages of 18 and 25 years (30\%). Thirty inmates, representing $7.5 \%$ of the study population, were found to be under aged, having ages below the legal age of 18 years. The age distribution of the sample size was normally distributed when compared to a theoretical distribution using the one sample kolmogorov Smirnov Test (statistic $=0.237, \mathrm{df}=400, \mathrm{p}$-value $=0.000$ ), and as illustrated or in the Histogram below. 392 were males representing $98 \%$ of the sample population, while 8 were females ( $2 \%$ of the sample population) using the principle of proportionate allocation (Table 1).

A logistic regression analysis was conducted to predict risk for depression among 400 inmates using age, marital status, and place of living as predictors. A test of the full model against a constant only model was statistically significant, indicating that the predictors as a set reliably distinguished those with higher risk of depression and those who do not. (Chi-square $=24.29, \mathrm{p}=.002$, with $\mathrm{df}=8$ ). Nagelkerke's $\mathrm{R}^{2}$ of 0.079 indicated a moderately strong relationship between prediction and grouping. The Wald criterion demonstrated that only place of living made a significant contribution to prediction $(\mathrm{p}=.014)$. Age and marital status were not significant predictors. $\operatorname{EXP}(\mathrm{B})$ value indicates that when place of living is decreased by one unit (one person) the odds ratio is 0.3 times as large and therefore urban dwellers $1 / 0.3=$ about 3 times likely to be depressed when compared with rural and semi-urban dwellers.

\section{Severity of depression among inmates}

The severity of depression was assessed from the scores on the Beck Depression Inventory (BDI). Scores of 11-20 indicate mild depression, 21-30 moderate depression, 31-40 severe and $41^{+}$extreme. Fifty seven (14.2\%) scored for mild depression, 67 (16.8\%) for moderate and 37 (9.2\%) for severe depression. 8 (2.0\%) scored for extreme. Two hundred and thirty one inmates (57.8.0\%) had no significant score.

\section{Prevalence and pattern of depression among prison inmates}

All the 169 subjects who scored greater than 10 using the Becks Depression Inventory (BDI), were interviewed in the second phase 
of the study, with the depression module of the Schedule for Clinical Assessment in Neuropsychiatry version 2.1(SCAN 2.1) and the computer algorithm was used to generate an ICD-10 diagnosis. Based on this, 169 subjects $(42.2 \%)$ of the study population fulfilled the criteria for current depressive disorder of whatever form.

Among the population with depression, 59 (14.8\%) met criteria for mild depression with somatic symptoms, 57 (14.2\%) for moderate depression with somatic symptoms, 25(6.2\%) severe depression without psychotic symptoms and 18 (4.5\%) for severe depression with psychotic symptoms. Ten $(2.5 \%)$ had no SCAN depression. The BDI negatives were screened in the ratio of $1: 10$ and two (2) inmates were found to have depression.

\section{Validity of BDI by SCAN 2.1}

One hundred and fifty nine $(39.7 \%)$ of the patients met SCAN criteria for depression while 169 (42.2\%) scored for depression on the BDI. The sensitivity and specificity of the BDI is calculated as follows (Table 2).

\section{Discussion}

\section{Socio-demographic factors}

The youngest and oldest inmates in this study were 14 and 90 years respectively, with a mean age of 33.8 this is close to findings in other

\begin{tabular}{|c|c|}
\hline Variable & n (\%) \\
\hline \multicolumn{2}{|l|}{ Sex } \\
\hline Male & $392(98)$ \\
\hline Female & $8(2)$ \\
\hline \multicolumn{2}{|l|}{ Age } \\
\hline$<18.00$ & $30(7.5)$ \\
\hline $18.00-25.00$ & $120(30.0)$ \\
\hline $26.00-33.00$ & $93(23.2)$ \\
\hline $34.00-41.00$ & $69(17.2)$ \\
\hline $42.00-49.00$ & $35(8.8)$ \\
\hline $50.00-57.00$ & $19(4.8)$ \\
\hline $58.00-65.00$ & $18(4.6)$ \\
\hline$>65$ & $16(3.9)$ \\
\hline \multicolumn{2}{|l|}{ Religion } \\
\hline Christianity & $352(88.0)$ \\
\hline Islam & $45(11.2)$ \\
\hline African Traditional Religion & $2(0.5)$ \\
\hline Others & $1(0.3)$ \\
\hline Level of Education & $40(10.0)$ \\
\hline No formal Education & $196(49.0)$ \\
\hline Primary Education & $28(7.0)$ \\
\hline Junior Secondary Education & $111(27.8)$ \\
\hline Senior Secondary Education & $10(2.5)$ \\
\hline Post-Secondary Education other than University & $15(3.7)$ \\
\hline \multicolumn{2}{|l|}{ Employment Status } \\
\hline Yes & $270(67.5)$ \\
\hline No & $130(32.5)$ \\
\hline \multicolumn{2}{|l|}{ Place of living (Residential Structure) } \\
\hline Urban & $276(69.0)$ \\
\hline Rural & $92(23.0)$ \\
\hline Semi-urban & $32(8.0)$ \\
\hline
\end{tabular}

Descriptive statistics: $n=$ frequency, $\%=$ percentage

Table 1: Socio-demographic Profiles of Inmates

\begin{tabular}{|c|c|c|c|}
\hline BDI score & $\begin{array}{c}\text { SCAN depression } \\
\text { present }\end{array}$ & SCAN depression absent & Total \\
\hline$\geq 10$ & $159=\mathrm{a}$ & $10=\mathrm{b}$ & $169=\mathrm{r} 1$ \\
\hline$<10$ & $2=\mathrm{c}$ & $229=\mathrm{d}$ & $231=\mathrm{r} 2$ \\
\hline Total & $161=\mathrm{c} 1$ & $239=\mathrm{c} 2$ & $400=\mathrm{t}$ \\
\hline
\end{tabular}

Confidence level $=95 \%$

$$
\begin{aligned}
& \text { Sensitivity }=\mathrm{a} / \mathrm{c} 1=\frac{159}{161} \times 100 \%=98.75 \% \text { or } 0.98 \\
& \text { Specificity }=\mathrm{d} / \mathrm{c} 2=\frac{229}{239} \times 100 \%=95.81 \% \text { or } 0.95 \\
& \text { Apparent prevalence of depression }= \\
& \qquad \frac{161}{400} \times 100 \%=39.75 \% \text { or } 0.39
\end{aligned}
$$

True Prevalence $=$ Apparent pervalence + Specificity -1 Sensitivity+Specificity -1

$$
\begin{array}{cl}
\frac{0.397+0.958-1}{1.0+0.958-1} & \frac{0.355}{0.95}=0.3705=37.05 \% \\
\text { Table 2: Validity of BDI by SCAN } 2.1 &
\end{array}
$$

studies in other parts of Nigeria and elsewhere. It was in a study by Fatoye, in Ilesha Nigeria, the youngest was 15 years of old, while the oldest was 70 years old with a mean of 31.2 years [14]. The mean age of 33.7 years in a similar study in South Africa [23], was consistent with the mean age found in this study. The import of this finding of young children in adult prisons is that international attention to serious offending by children has increased recently as postulated in a recent study in 2015 .

Out of 100 inmates investigated in Benin, 93\% were males, with a mean age; of participants was 31.4 years [24]. Participants in a prison study in Iran were aged 17-76 years, with a mean age of 32.7 years [25]. The age range of the sample was 16-80 with a mean of 33.5 years in another study [26-29]. However the mean age of 36.38 in the Indian study differs but is comparable to the mean age in this study which was 33.8 . In 47 surveys $(12,859$ prisoners) that included information on age, weighted mean age of prisoners was 29 years [9]. There was preponderance of subjects belonging to age group 30 years and below in a previous study [14] which is in conformity with the finding in this study, that there was preponderance of inmates below 30 years. The higher preponderance among males may be explained by fact that crime rate is higher among males and they are also more likely to reoffend.

\section{Prevalence of Depression among the prison inmates and the correlates}

The prevalence estimates were higher than those published in similar studies [30-41], which agrees with our hypothesis. In this study, the prevalence of depression using Becks depression inventory which was used to evaluate the presence of depressive symptoms using four levels of intensity revealed that $14.2 \%$ met the criteria for mild depression, $16.8 \%$ for moderate, $9.2 \%$ for severe and $2 \%$ for extreme in a prison study involving a heterogeneous group of inmates.

The prevalence varied after using SCAN, were $14.8 \%$ mild depression with somatic features, $14.2 \%$ for moderate depression, $6.2 \%$ for severe depression without psychotic features while $4.5 \%$ was for severe depression with psychotic features. The values obtained were lower than that obtained in a similar study. In that study, 33\% met criteria for mild depression, $29 \%$ met criteria for moderate depression, 
while $20 \%$ met criteria for severe depression [7]. This variation may be due to differences in populations studied, because in the study referred, only incarcerated women were considered while in this study, both males and females were included. In this study, symptomatic clustering is applied towards the goal of clinical subtyping, based on the presence or absence of somatic complaints and psychotic features, in addition, to a stratification based on disease severity. This however raises the question as to why additional clinical aspects such as chronicity, recurrence, functional shift, melancholic or atypical features were not similarly considered. This should be understood in the context of the limited utility of a purely clinical approach to Major Depressive Disorder subtyping [42].

The true prevalence rate of depression from this study was $37 \%$ and this was higher than values from similar studies. Assadi et al, in 2006 found that $29 \%$ met the criteria for major depressive disorder [31] an average prevalence of $10 \%$ for major depression among male prisoners and $12 \%$ for females [14]. A prison survey in the United States in 2006 , found that $24 \%$ of state prison inmates, $16 \%$ of federal inmates and $30 \%$ of local jail inmates had a major depressive disorder [30,34]. Incarcerated adolescents had significantly more psychiatric disorders than adolescents in the community group with a high prevalence rate of depression of $30.6 \%$.. In a study in New Zealand, $1 / 4^{\text {th }}$ of all prisoners had suffered a major depressive disorder with $11.1 \%$ of women, $10 \%$ of remand men and $5.9 \%$ of sentenced men [23]. Lifetime prevalence rates are $32.1 \%$ for women, $20.6 \%$ for remand and $22.6 \%$ of sentenced men. Prevalence rate was $16 \%$ in another study $[27,28]$. Aghaghowe, found a prevalence of $23 \%$ in a study in Benin Nigeria [24,25]. In another study the rate of depression in the study was 30\% (23-36\%) among elderly inmates [32]. The prevalence in a French study was $17.9 \%$ [19] and was $7.9-15.2 \%$ in another study $[29,35]$. In a recent study in a maximum security prison in Jos, Nigeria, the prevalence rate was $30.8 \%$ ${ }^{37}$. However, this prevalence rate correlated with the lifetime prevalence of $37 \%$ in a case control study [37] and $36 \%$ found in a similar study [36]. The finding of a prevalence of depression of $35.8 \%$ by Yusuf et al was close to the prevalence in this study [26].

Several explanations can be suggested for the differences observed. First, the instruments used in the studies were different; the locations of the studies were different, with none conducted in Port Harcourt. The majority of the studies were conducted many years ago and prevalence of depression may have changed within the period. Another possibility for the comparatively lower prevalence in the prison in developed countries may be because of the better prison environment in those climes and maybe the supply of better health services to the prisoners. The harsher prison condition noted in the location of the prison for the present study may have contributed to the higher prevalence noted. The lower rate of $23 \%$ obtained in a similar study in Benin, may be related to the fact that Port Harcourt prisons, is a maximum security prison with a bigger capacity and houses different kinds of crimes compared with the medium security prison earlier which has a smaller capacity for inmate. It may also be concluded from the present study that prisons may apparently contain a larger number of people with untreated major depression. It may also be an indication that the proportion of inmates with mental illness including depression is increasing [36]. Furthermore, the strong association between drug abuse and depression should be noted here, since $2 / 3^{\text {rd }}$ or $68.2 \%$ of the study population, had issues with drug abuse, which is in conformity with the finding in another study [38].
The prevalence of depression was also noted to vary depending on the class of inmates. Depressive episodes were more among under trials, when compared to that of convicted prisoners [31]. The higher rate among under trials may not be unconnected with the fact that for most of them their fate in jail is uncertain with difficulties they face before arraignment in court, unlike the convicted inmates that already know their fate. Prevalence was also commoner among males as found in $41.0 \%$ than the $1.2 \%$ found among the females. It was also commoner among males, single and more in the second decade of life. This is consistent with the finding that majority in of inmates were single and under the age of 30 years [37]. This may be because males are overrepresented in jail and they are more likely to be single and of a young age.

Multivariate analysis using multiple logistic regressions revealed that the Socio-demographic factors include: Living in an urban area $(\mathrm{OR}=0.31, \mathrm{CI}=0.14-0.68, \mathrm{p}=0.00)$ was statistically significant, which agrees with our hypotheses that socio-demographic characteristics may be predictors of depression.

Results from multivariate analysis also agree with the fact that social, demographic, and environmental influences affect the mental health of inmates [33]. The results from the regression analysis however differed from the risk factors contributing to depression in a similar study among incarcerated women in Brazil which found the presence of co-morbidities $(\mathrm{OR}=5.43)$, religion $(\mathrm{OR}=8.81)$, eating habits $(\mathrm{OR}=5.7)$ and visitors $(\mathrm{OR}=11 . \mathrm{I})$. The difference noted may be due to the target populations studied, because only women were used in the Brazilian study, but heterogeneous group of inmates were used in this study. Statistical instruments used were also different which also may have contributed to the differences noted (Tables 3 and 4).

Finally, the fact that the prevalence of depression in high in Port Harcourt prisons and those affected were either taking medication, or getting any specialist care, is a pointer, that depression is a significant source of morbidity among prison inmates in line with our hypotheses [43].

\section{Contribution to field of psychiatry and implications of study findings}

This is the first study of its kind in Port Harcourt prisons, southern Nigeria. Therefore, findings from this research will form a baseline on which further research on issues can be conducted. The present study confirms previous findings and contributes additional evidence that definitely adds to the body of knowledge on the burden of mental illness among the incarcerated, which has been hitherto a neglected area of research raising the awareness for further research to bring to fore the need to improve care delivery in correctional facilities in general and mental illness in general.

The evidence from this study, suggests that over one third had a major depressive disorder. This finding agrees with the fact, that there is an urgent need for the improvement of psychiatric services in prison settings and other public health institutions in developing nations like Nigeria, in order to minimize the sufferings of the inmates, due to various health neglects. It is obvious, that the health systems in developing countries, is poorly organized and funded. The results of this research support the idea, that there is also the need to improve capacity training and competence, in the diagnosis and management of prisoners with mental illness like depression, which is a pressing international public health issue. Prisons service can provide a better 


\begin{tabular}{|c|c|}
\hline Variable & n (\%) \\
\hline \multicolumn{2}{|l|}{ Occupation } \\
\hline Legislators/CEOs/Managers & $3(0.8)$ \\
\hline Professionals & $13(3.2)$ \\
\hline Technicians/Associate Professionals & $49(12.2)$ \\
\hline Clerks & $3(0.8)$ \\
\hline Service Workers/Shop/Market/Sales Workers & $56(14.0)$ \\
\hline Skilled Agriculture/Fishery Worker & $26(6.5)$ \\
\hline Craft and related trade worker & $32(8.0)$ \\
\hline Plant and Machine Operators & $6(1.5)$ \\
\hline Elementary Occupation & $20(5.0)$ \\
\hline Armed Forces/ Police & $9(2.2)$ \\
\hline Workers not classified by Occupation & $46(11.5)$ \\
\hline Others & $7(1.8)$ \\
\hline Not employed & $130(32.5)$ \\
\hline \multicolumn{2}{|l|}{ Social Class } \\
\hline Class 1 & $12(3.0)$ \\
\hline Class 2 & $25(6.3)$ \\
\hline Class 3 & $101(25.3)$ \\
\hline Class 4 & $79(19.8)$ \\
\hline Class 5 & $183(45.8)$ \\
\hline \multicolumn{2}{|l|}{ Marital Status } \\
\hline Single & $257(64.3)$ \\
\hline Married & $118(29.4)$ \\
\hline Divorced & $3(0.8)$ \\
\hline Separated & $14(3.5)$ \\
\hline Widowed & $8(2.0)$ \\
\hline \multicolumn{2}{|l|}{ Living Arrangements } \\
\hline Alone & $153(38.5)$ \\
\hline Spouse & $107(26.8)$ \\
\hline Parents & $61(15.2)$ \\
\hline Siblings & $29(7.2)$ \\
\hline Relatives & $32(8.0)$ \\
\hline Sexual Partner & $18(4.5)$ \\
\hline \multicolumn{2}{|l|}{ Ethnic group } \\
\hline Ibo & $125(31.2)$ \\
\hline Ibibio/Annang & 66 (16.5) \\
\hline ljaw & $57(14.3)$ \\
\hline Ikwerre & $54(13.5)$ \\
\hline Hausa/Fulani & $39(9.7)$ \\
\hline Yoruba & $19(4.8)$ \\
\hline Non Nigerians & $2(0.5)$ \\
\hline Others & $38(9.5)$ \\
\hline
\end{tabular}

\begin{tabular}{|l|c|c|c|c|c|c|c|}
\hline \multicolumn{1}{|c|}{ Variable } & B & SE & P-value & ORf & \multicolumn{2}{|c|}{$\mathbf{9 5 \%}$ Cl for OR } \\
\hline Age & & (B) & & & Lower & Upper \\
\hline Marital Status & 0.96 & 0.95 & 0.313 & 1.1 & 0.91 & 1.32 \\
\hline Singlet & & & 0.06 & & & \\
\hline Married & -0.8 & 0.52 & 0.12 & 0.44 & 0.16 & 1.25 \\
\hline Divorced & -0.599 & 0.56 & 0.29 & 0.54 & 0.18 & 1.67 \\
\hline Separated & -0.994 & 1.33 & 0.45 & 0.37 & 0.02 & 5.09 \\
\hline Widow/Widower & 0.98 & 0.83 & 0.23 & 2.68 & 0.52 & 13.72 \\
\hline $\begin{array}{l}\text { Cohabiting with the opposite } \\
\text { sex }\end{array}$ & 0.22 & 0.89 & 0.804 & 1.24 & 0.21 & 7.21 \\
\hline Place of Living & -1.16 & 0.39 & 0.004 & 0.313 & 0.14 & 0.68 \\
\hline Urban & 0.98 & 0.12 & 0.024 & 0.375 & 0.16 & 0.87 \\
\hline Rural & 1.01 & 0.68 & 0.138 & 2.75 & & \\
\hline Constant & & & 0.014 & & & \\
\hline
\end{tabular}

Table 4: Relationship between depression and the socio-demographic factors

is a reflection of the situation in most prisons of the developing world. There is the possibility therefore, that the local lessons can then indeed be translated into national as well as global action.

\section{Conclusion}

Data from this study shows that the burden of depression in this vulnerable and marginalized population poses a serious challenge to researchers and clinicians alike. This and the other findings above, point towards the need for coordinated care planning between the prison authority, psychiatric services, and the criminal justice system in order to promote public health of the inmates. It is noteworthy that undetected, under-detected and under-treated depression in the prisoners is an increasing public health problem.

\section{Limitations of the Study}

A number of limitations were noted in the course of the study. These factors however did not affect substantially the results of this research. They include-

1. The study relied on self-report for accounts (self-reported data contain several potential sources of bias.

2. No opportunity to corroborate information given from collateral informants.

3. There was no access to detailed previous psychiatric records.

A further limitation was that there were no prison's criminal and health records to confirm or refute self-reported statements. No proper and adequate medical records were kept at the Port Harcourt Prisons.

\section{Acknowledgement}

Nigerian prison service, Dr Paul Wakama, Mr Emma of the Prison Infirmary, Port Harcourt, Prof P.C Stanley, Drs Obi, Ibeawuchi, Ugbomah, Chukwujekwu, Essien, Adiukwu, Adesokun, all of University of Port Harcour Teaching Hospital, Nigeria and all those involved in the care of the incarcerated.

\section{References}

1. Muakad IB (1998) Prisão albergue. (3rd edtn), São Paulo, Brazil: Atlas. 
2. Jordan BK, Schlenger WE, Fairbank JA, Caddell JM (1996) Prevalence of psychiatric disorders among incarcerated women. II. Convicted felons entering prison. Arch Gen Psychiatry 53: 513-519.

3. Teplin LA, Abram KM, McClelland GM (1996) Prevalence of psychiatric disorders among incarcerated women. I. Pretrial jail detainees. Arch Gen Psychiatry 53: 505-512.

4. Moraes P, Dalgalarrondo P (2006) Women imprisoned in São Paulo. Mental health and religiosity. J Bras Psiq 55: 50-56.

5. Fernandes R, Hirdes A (2006) Convicts' perception of prison as deprivation of liberty. Rev Enf UER 14: 418-424.

6. Morakinyo O. (2002) The nature and diagnosis of depressive disorders in Africans. In Morakinyo O (ed): Handbook for students on mental health posting Ile-Ife: The Department of Mental Health, Obafemi Awolowo University/ Obafemi Awolowo University Teaching Hospital Complex.

7. Ohaeri JU, Jegede RO (1991) Depression and the general medical practitioner in Nigeria. Medicare 6: 7-11.

8. Ulzen TP, Hamilton $H$ (1998) The nature and characteristics of psychiatric comorbidity in incarcerated adolescents. Can J Psychiatry 43: 57-63.

9. Joukamma M (1995) Psychiatric morbidity among Finnish Prisoners with special reference to socio-demographic factors: Results of the Health Survey of Finnish Prisoners (Wattu Project). Forensic Sci Int 73: 85-91.

10. Kadiri M (2014) Depression: a Global Crises. Mind matters with celebrity shrink.

11. Ekers David (2010) Behavioural activation for Depression delivered by mental Health Nurses. A systematic review of the evidence and controlled clinical trial. Int. J of Mental Health Nurs 3: 3.

12. Parkes JH, Freshwater DS (2012) The journey from despair to Hope. An exploration of the Phenomenom of psychological distress in women residing in secure Mental Health Services. J Psychiatr Ment Health Nurs 19: 618-628.

13. Kuosmanen L (2010) Attitudes towards Depression treatment in Primary care in Finland. $16^{\text {th }}$ International Network for Psychiatric Nursing Research (NPNR) Conference, Oxford, England.

14. Fatoye FO, Fatoye GK, Oyebanji AO, Ogunro AS (2006) Psychological characteristics as correlates of emotional burden in incarcerated offenders in Nigeria. East Afr Med J 83: 545-552.

15. Ogunlesi AO, Makanjuola JDA, Adelekan ML (1988). Offenders admitted to the Neuropsychiatric Hospital, Aro. Abeokuta. A ten year review. West African Journal of Medicine 7: 210-215

16. Dooley E (1990) Prison suicide in England and Wales, 1972-87. Br J Psychiatry 156: $40-45$.

17. Bolton $P$, Neugebauer R, Ndogoni L (2002) Prevalence of depression in rural Rwanda based on symptom and functional criteria. J Nerv Ment Dis 190: 631637.

18. Araoye M (2003) Research methodology with statistics for Health and Social Sciences, Nathadex publishers 115-129.

19. Lindquist $\mathrm{CH}$, Lindquist CA (1997) Gender differences in distress: mental health consequences of environmental stress among jail inmates. Behav Sci Law 15: 503-523.

20. Heidi W (2006) Depression as a leading contributor to Global burden of disease. Population reference Bureau.

21. Chisholm D, Sanderson K, Ayuso-Mateos JL, Saxena S (2004) Reducing the global burden of depression: population-level analysis of intervention costeffectiveness in 14 world regions. Br J Psychiatry 184: 393-403.

22. Bartol CR, Bartol AM (1994) Psychology and Law: Research and Application. (2nd edn), Pacific Grove, CA

23. Department of corrections. (1999) The National study of psychiatric Morbidity in New Zealand Prisons. An investigation to the prevalence of psychiatric disorders among New Zealand inmates.
24. Agbahowe SA, Ohaeri JU, Ogunlesi AO, Osahon R (1998) Prevalence of psychiatric morbidity among convicted inmates in a Nigerian prison community. East Afr Med J 75: 19-26.

25. Assadi SM, Noroozian M, Pakravannejad M, Yahyazadeh O, Aghayan S, et al. (2006) Psychiatric morbidity among sentenced prisoners: prevalence study in Iran. Br J Psychiatry 188: 159-164.

26. Yusuf AD, Ajiboye PO, Issa BA, Buhari OI (2011) Prevalence and risk factors for psychiatric disorders among youths in a Borstal Inst. in Nigeria. Journal of Parkistan Psych Society 8: 22.

27. Singh G, Verma H (1976) Murder in Punjab. A psychosocial Study. Indian. J. Psych 19: 60-62.

28. Goyal SK, Singh P, Gargi PD, Goyal S, Garg A (2011) Psychiatric morbidity in prisoners. Indian J Psychiatry 53: 253-257.

29. Taylor PJ, Parrott JM (1988) Elderly offenders. A study of age-related factors among custodially remanded prisoners. Br J Psychiatry 152: 340-346.

30. Fazel S, Hope T, O'Donnell I, Jacoby R (2001) Hidden psychiatric morbidity in elderly prisoners. Br J Psychiatry 179: 535-539.

31. Thom-Rita G (2008) Depression and Anxiety in HIV infected individuals attending HIV treatment facilities at various sites in South Africa: Occurrence and related factors. A descriptive Analytic Study. 17-30.

32. Nseluke M, Siziya S (2011) Prevalence and socio-demographic correlates for mental illness among inmates at Lusaka Central Prison, Zambian Med J 38 : $10-20$.

33. Beverly C, Repper J (2010) Mental Health services and Prisoners. An updated review: An Epidemiological review of mental disorders in prisons. Chapter 5 p84-104.

34. Torrey E, Kennard S, Eslinger S, Lamb R, Pavle J. (2010) More mentally ill persons are in jails and prisons than Hospitals. A survey of the states.

35. National Commission on Correctional Health Care (2002) The Health status of soon-to-be released inmates: A report to Congress.

36. Criminal Code CAP "C38”. Laws of the Federation, Federal Republic of Nigeria.

37. Nwaogwugwu N, Alao O, Egwuonwu C (2012) Militancy and Insecurity in the Niger Delta: Impact on the flow of direct foreign investment. Arabian J of Business \& Manage 2: 23-30.

38. Sarkin J (2009) Prisons in Africa. Evaluation from a human rights perspective Sur International Human Rights Journal 9: 22-49.

39. Grohol J (2013) Depression and depressive disorders. Psych Central.

40. Bulman P, Garcia M, Hernon J (2012) Study questions raises questions about psychological effects of solitary confinement. NIJ Journal 269

41. Global Prison Trends 2015. Prison Reform International Office.

42. Sloma A (2015) The Prison of Depression: Mental Health of the incarcerated. The Humanology Project.

43. Shahid I, Aftab M, Yousaf Z, Nagvi S, Hashmi A (2014) Prevalence of depression among male prisoners at an urban Jail in Pakistan. Health MED 8: 699. 